\title{
Prevalence of primary dysmenorrhea, its intensity, impact and associated factors among female students' at Gondar town preparatory school, Northwest Ethiopia
}

\author{
Abere Woretaw Azagew ${ }^{*^{*}} \mathbb{D}$, Destaye Guadie Kassie ${ }^{2}$ and Tarkie Abebe Walle ${ }^{3}$
}

\begin{abstract}
Background: Primary dysmenorrhea is defined as a crampy pain in the lower abdomen before or during the menstrual period in the absence of any pelvic pathology. It is the leading motherhood problem worldwide but there is limited evidence on the prevalence of primary dysmenorrhea in the study area as well in Ethiopia. Researching primary dysmenorrhea helps to focus on the treatment plan. The study aimed to assess the prevalence, intensity, impact, and associated factors of primary dysmenorrhea among female students at Gondar town preparatory school.

Methods: A cross-sectional study design conducted among female students at Gondar town Preparatory School from May 1-10/2017. A total of 459 study participants were used. A simple random sampling technique was used to select study participants. A self-administered structured questionnaire was employed. Epi Info version 7 and SPSS version 20 were used for data entry and analysis respectively. A binary logistic regression model was computed. Variables having a $p$-value $<0.05$ in the multivariate logistic regression model were considered as statistically significant.

Results: A total of 459 female students participated in the study with a response rate of $96.29 \%$. The prevalence of primary dysmenorrhea among female students was found to be $64.7 \%$ (95\% Cl; 60.2-69.2\%). Around 61\% reported moderate intensity of menstrual pain and $50.7 \%$ complain about lower abdominal pain. Sixty-five percent of study participants reported that absenteeism from school was the impact of menstrual pain. Having irregular monthly menstrual cycle (AOR $=1.70,95 \% \mathrm{Cl} ; 1.02,2.84)$ and positive family history of dysmenorrhea $(\mathrm{AOR}=5.19,95 \% \mathrm{Cl}$ : $3.21,8.37$ ) were significantly associated with primary dysmenorrhea.
\end{abstract}

Conclusions: The prevalence of primary dysmenorrhea was found to be high. Having an irregular monthly menstrual cycle and a positive family history of dysmenorrhea were determinants of primary dysmenorrhea.

Keywords: Female, Impact, Intensity, Primary dysmenorrhea, Prevalence, Preparatory school students

\footnotetext{
*Correspondence: wabere@ymail.com; Abere.Woretaw@uog.edu.et

${ }^{1}$ Department of Medical Nursing, School of Nursing, College of Medicine and

Health Sciences, University of Gondar, Gondar, Ethiopia

Full list of author information is available at the end of the article
}

(c) The Author(s). 2020 Open Access This article is distributed under the terms of the Creative Commons Attribution 4.0 International License (http://creativecommons.org/licenses/by/4.0/), which permits unrestricted use, distribution, and reproduction in any medium, provided you give appropriate credit to the original author(s) and the source, provide a link to the Creative Commons license, and indicate if changes were made. The Creative Commons Public Domain Dedication waiver (http://creativecommons.org/publicdomain/zero/1.0/) applies to the data made available in this article, unless otherwise stated. 


\section{Background}

Dysmenorrhea is pain associated with menstruation. It is the most commonly reported menstrual disorder in women. More than half of women who menstruate have pain for 1-2 days each month [1, 2]. It is an extremely common and sometimes debilitating condition for women of reproductive age [3]. Its prevalence varies from between 16 to $91 \%$ in reproductive age women [4]. Dysmenorrhea is classified as primary and secondary dysmenorrhea. Secondary dysmenorrhea is caused by a disease or condition such as infection, ovarian cyst, and endometriosis [5].

Primary dysmenorrhea is defined as cramping pain in the lower abdomen before or during the menstruation period in the absence of any pelvic pathology [6]. It is the leading women hood problem that affects $90 \%$ of adolescent girls and more than 50\% menstruating women [7]. The pathophysiology of primary dysmenorrhea is due to increased and/or abnormal uterine activity as a result of increased production and release of prostaglandins $[8,9]$. The clinical feature of Primary Dysmenorrhea is frequent and crampy pain which mainly affects the lower abdomen and radiates to the back or thigh [6].

Fatigue emotional disturbance, abdominal distension, nausea, vomiting, and sleep disturbances are associated with symptoms of dysmenorrhea [4]. The causes of primary dysmenorhea were not well studied, but the common risk factors are a positive family history of dysmenorrhea, not use of oral contraceptive, smoking, higher severity of bleedings, shorter/longer menstrual period interval, stress, and menstrual cycle irregularity $[1,2,4,10]$.

Daily activity limitation, absenteeism from school/ work, social withdrawal, decrease academic performance, and increased health care medical costs are the negative effect of primary dysmenorrhea [4, 10-14]. Use of oral contraceptives [3], non-steroidal anti-inflammatory medications [15, 16], herbal medicines [17], massage [18], and lifestyle modification [19] are treatment strategies to reduce dysmenorrheic pain.

In Ethiopia, there is limited evidence on the prevalence, intensity, impact, and associated factors of primary dysmenorrhea among preparatory school female students in the study area.

\section{Methods}

\section{Study design and settings}

A cross-sectional survey was conducted among female preparatory school students in Gondar town from May $1-10 / 2017$. Gondar town is one of the historical towns in Ethiopia. It is found in Amhara regional state, Northwest part of Ethiopia. It is about $750 \mathrm{~km}$ away from Addis Ababa the capital city of Ethiopia. In Gondar town, there are five preparatory schools of which three preparatory schools were selected.

\section{Source and study population}

Female students who undergo their education in Gondar town preparatory school were considered as source population whereas female students who were present in the selected preparatory school during the data collection period were taken as the study population.

\section{Inclusion / exclusion criteria}

Female students who undergo their education in the selected preparatory school at Gondar town were included in the study whereas female students who had a known diagnosed medical history of pelvic pathology were excluded in the study.

\section{Sample size and sampling procedures}

The sample size was determined by using a single population proportion formula using the assumption of; $95 \%$ level of confidence, $4 \%$ marginal error and by taking the prevalence of dysmenorrhea from a previous study (77.6\%) [12]. With these assumptions, the sample size became 417. Anticipating a10\% nonresponsive rate, the required sample size was 459.The study participants were taken from the selected (Azezo, Fasiledes, and Angereb) preparatory schools using stratified random sampling with proportional allocation. The study participants were selected using a simple random sampling technique.

\section{Data collection tools and procedures}

A pretested structured questionnaire was used. The questionnaire adopted from previous literature [12, 20]. The questionnaire had three parts namely socio-demographic characteristics, obstetric /gynecological related characteristics and presence of primary dysmenorrhea, intensity and their impacts. Pain associated with menstruation without any pelvic pathology was considered as primary dysmenorrhea.

The irregular monthly menstrual cycle is taken as longer/heavy bleeding than a usual menstrual cycle [21]. Using a verbal report from the Numeric Rating Scale (NRS); the intensity of primary dysmenorrhea related pain was considered as no pain $(\mathrm{NRS}=0)$, mild pain $(\mathrm{NRS}=1-3)$, moderate pain $(\mathrm{NRS}=4-6)$, and severe pain (NRS $=7-10)$ [22]. The data were collected by five nurses (three data collectors and two supervisors) from May 1-10/2017 using a self-administered technique.

\section{Data processing and analysis}

Data were checked, coded, and entered into Epi Info version 7 and exported to SPSS version 20 for analysis. Descriptive statistics such as frequency and percentage were used. Tables and bar graphs were used to display the 
findings. A binary logistic regression model was used to identify factors associated with primary dysmenorrhea. Variables whose $p$-value $\leq 0.2$ in the bivariable logistic regression analysis were taken into multivariable logistic regression analysis. For the bivariable logistic regression; Crude Odds Ratio (COR) and 95\% CI, and for the multivariable logistic regression; Adjusted Odds Ratio (AOR) and $95 \% \mathrm{CI}$ were calculated. Variables having a $p$-value < 0.05 in the multivariate logistic regression model were considered as statistically significant. The backward stepwise logistic regression analysis method was used. Hosmers and Lemishow goodness of fit test were done.

\section{Results}

Socio-demographic characteristics of respondents

A total of 459 female students were enrolled in the study with a response rate of $96.29 \%$. Among study participants,
232(52.5\%) were aged less than 18 years, 286(64.7\%) were grade eleven, 398(90\%) were single, and 403(91.2\%) were Orthodox Christian followers. More than threefold (94.3\%) of study participants were Amhara by ethnicity. The majority $(86.7 \%)$ of the respondents were urban dwellers and $370(83.7 \%)$ were lived with their family home. Regarding family education, more than half of respondent mothers' were illiterate and 294(66.5\%) were housewives by their occupational status. Above one-third (40\%) study participants carry out sports activity (Table 1 ).

\section{Obstetrics and gynecology related characteristics}

Among study participants, 250(56.6\%) experienced 1st menstruation at the age group of $12-14$ years. Nearly three-fourths $(73.5 \%)$ of study participants had regular monthly menstrual cycle pattern and the vast majority (91.9\%) of study participants reported menstrual

Table 1 Socio-demographic characteristics of female students at Gondar town preparatory school Northwest Ethiopia, 2017, $(n=442)$

\begin{tabular}{|c|c|c|c|}
\hline Variables & Category & Frequency (n) & Percent (\%) \\
\hline \multirow[t]{2}{*}{ Age in year } & $\geq 18$ & 210 & 47.5 \\
\hline & $<18$ & 232 & 52.5 \\
\hline \multirow[t]{2}{*}{ Student grade } & $11^{\text {th }}$ & 286 & 64.7 \\
\hline & $12^{\text {th }}$ & 156 & 35.3 \\
\hline \multirow[t]{3}{*}{ Religion } & Orthodox Christian & 403 & 91.2 \\
\hline & Muslim & 28 & 6.3 \\
\hline & Protestant & 11 & 2.5 \\
\hline \multirow[t]{4}{*}{ Marital status } & Single & 398 & 90 \\
\hline & Married & 39 & 8.8 \\
\hline & Divorced & 4 & 0.9 \\
\hline & Widowed & 1 & 0.2 \\
\hline \multirow[t]{3}{*}{ Ethnicity } & Amhara & 417 & 94.3 \\
\hline & Qimant & 13 & 3 \\
\hline & Tigray & 12 & 2.7 \\
\hline \multirow[t]{2}{*}{ Origins of residence } & Urban & 383 & 86.7 \\
\hline & Rural & 59 & 13.3 \\
\hline \multirow[t]{3}{*}{ Place of residence } & At family home & 370 & 83.7 \\
\hline & With other relatives & 37 & 8.4 \\
\hline & At dormitory & 35 & 7.9 \\
\hline \multirow[t]{4}{*}{ Mother's education } & Illiterate & 228 & 51.6 \\
\hline & Primary school & 61 & 13.8 \\
\hline & Secondary school & 95 & 21.5 \\
\hline & College and above & 58 & 13.1 \\
\hline \multirow[t]{3}{*}{ Mother's Occupation } & Government employed & 88 & 19.9 \\
\hline & Housewife & 294 & 66.5 \\
\hline & Merchant & 50 & 13.6 \\
\hline \multirow[t]{2}{*}{ Sport activity } & Yes & 177 & 40 \\
\hline & No & 265 & 60 \\
\hline
\end{tabular}


bleeding duration $\leq 7$ days. One hundred eighty- three (41.4\%) of study participants reported that they had a positive family history of dysmenorrhea (Table 2 ).

\section{Prevalence, intensity, and impact of primary dysmenorrhea}

The prevalence of primary dysmenorrhea was found to be $64.7 \%(95 \% \mathrm{CI} ; 60.2,69.2 \%)$ of which nearly half (50.7\%) of them complain about lower abdominal pain (Fig. 1). The intensity of pain during menstruation was 83(29\%), 174(60.8\%), and 29(10.2\%) reported having mild, moderate, and severe menstrual pain respectively. Seventy-three $(25.5 \%)$ used analgesic medications. Paracetamol 44(60.3\%), diclofenac 15(20.5\%), and Ibuprofen 14(19.2\%) were used to relieve the pain. Absenteeism from school 186(65\%), limited activity daily living $57(20 \%)$ and anxiety $43(15 \%)$ were the impact of menstrual pain reported by study participants.

\section{Factors associated with primary dysmenorrhea}

All variables with $p$-value $\leq 0.2$ in the bivariable logistic regression analysis were taken into multivariable analysis. Having an irregular monthly menstrual cycle and a positive family history of dysmenorrhea were significantly associated with primary dysmenorrhea in multivariable logistic regression analysis (Table 3).

\section{Discussion}

The prevalence of primary dysmenorrhea was found to be $64.7 \%$ (95\% CI; 60.2, 69.2\%). Lower abdominal pain (50.7\%), back pain (25.5\%), headache (16.8\%), and fatigue (6.7\%) were the commonly reported symptoms among study participants. Nearly $61 \%$ reported moderate intensity of menstrual pain. Sixty-five percent of study participants reported that absenteeism from school is the main impact of menstrual pain. The finding of this study is in line with a study conducted at Debre Tabor, Ethiopia $62.3 \%$ [23] and Chandigarh, India 61.33\% [24]. The finding of the current study was higher than a study in Canada (60\%), Japan (46,5\%) and (54.4\%), Tbilisi, Georgia (52.07\%), and Southern India (45\%) [25-29]. The variation is due to the assessment tool, method of data collection such as interviewing using a cell phone, use of clinical assessment like ultrasound and laboratory test, and sample size used.

To the contrary, the finding of the current study was lower than a study conducted in Iran (89.1\%), Turkey (72.7\%), Debre Birhan University (85.4\%) and University

Table 2 Obstetric and gynecological related characteristics of female students at Gondar town preparatory school Northwest Ethiopia, 2017, $(n=442)$

\begin{tabular}{|c|c|c|c|}
\hline Variables & Category & Frequency (n) & Percent (\%) \\
\hline \multirow[t]{2}{*}{ Age at menarche } & $12-14$ & 250 & 56.6 \\
\hline & $\geq 15$ & 192 & 43.4 \\
\hline \multirow[t]{2}{*}{ Monthly menstrual cycle } & Regular & 325 & 73.5 \\
\hline & Irregular & 117 & 26.5 \\
\hline \multirow[t]{2}{*}{ Menstrual bleeding duration (in days) } & $\leq 7$ & 406 & 91.9 \\
\hline & $>7$ & 36 & 36.1 \\
\hline \multirow[t]{3}{*}{ Estimated amount of menstrual flow /by no. of pads } & $\leq 2$ & 288 & 65.2 \\
\hline & $3-4$ & 141 & 31.9 \\
\hline & $>4$ & 13 & 2.9 \\
\hline \multirow[t]{2}{*}{ Any family planning method? } & Yes & 30 & 6.8 \\
\hline & No & 412 & 93.2 \\
\hline \multirow[t]{4}{*}{ Type of family planning used } & Depo provera & 10 & 33.3 \\
\hline & Pills & 8 & 26.7 \\
\hline & Implanol & 7 & 23.3 \\
\hline & IUCD & 5 & 16.7 \\
\hline \multirow[t]{2}{*}{ Family history of dysmenorhea } & Yes & 183 & 41.4 \\
\hline & No & 259 & 58.6 \\
\hline \multirow[t]{2}{*}{ Circumcision history } & Yes & 38 & 8.6 \\
\hline & No & 404 & 91.4 \\
\hline \multirow[t]{2}{*}{ Abortion history } & Yes & 10 & 2.3 \\
\hline & No & 432 & 97.7 \\
\hline
\end{tabular}




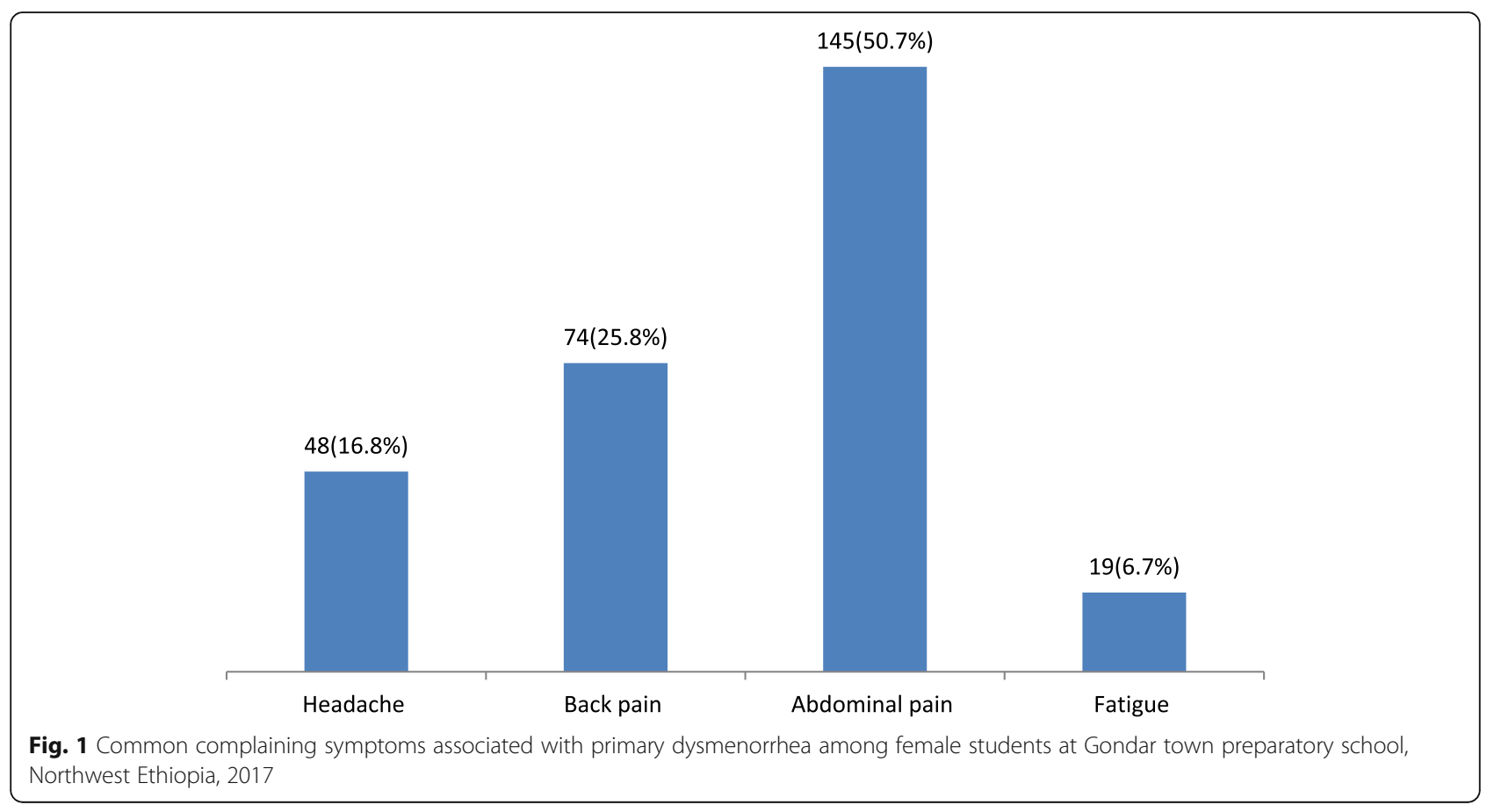

Table 3 Factors associated with primary dysmenorrhea among female students at Gondar town preparatory school Northwest Ethiopia, 2017, $(n=442)$

\begin{tabular}{|c|c|c|c|c|}
\hline \multirow[t]{2}{*}{ Variables } & \multicolumn{2}{|c|}{ Primary dysmenorrhea } & \multirow[t]{2}{*}{ COR, 95\% Cl } & \multirow[t]{2}{*}{$\mathrm{AOR}, 95 \% \mathrm{Cl}$} \\
\hline & Yes & No & & \\
\hline \multicolumn{5}{|l|}{ Place of residence } \\
\hline At family home & 239 & 131 & $1.216(0.599,2.471)$ & $1.442(0.650,2.471)$ \\
\hline With other relatives & 26 & 11 & $1.576(0.593,4.185)$ & $2.105(0.725,6.106)$ \\
\hline At dormitory & 21 & 14 & 1 & 1 \\
\hline \multicolumn{5}{|l|}{ Age at menarche } \\
\hline $12-14$ & 164 & 86 & $1.094(0.739,1.621)$ & $1.046(0.672,1.629)$ \\
\hline$\geq 15$ & 122 & 70 & 1 & 1 \\
\hline \multicolumn{5}{|l|}{ Monthly menstrual cycle } \\
\hline Regular & 200 & 125 & 1 & 1 \\
\hline Irregular & 86 & 31 & $1.734(1.086,2.767)$ & $1.701(1.019,2.839)^{\mathrm{a}}$ \\
\hline \multicolumn{5}{|c|}{ Menstrual bleeding duration } \\
\hline$\leq 7$ days & 262 & 144 & 1 & 1 \\
\hline$>7$ days & 24 & 12 & $1.099(0.534,2.263)$ & $1.081(0.467,2.502)$ \\
\hline \multicolumn{5}{|c|}{ Family history of menstrual pain } \\
\hline Yes & 153 & 30 & $4.832(3.047,7.661)$ & $5.188(3.214,8.373)^{a}$ \\
\hline No & 133 & 126 & 1 & 1 \\
\hline \multicolumn{5}{|l|}{ Circumcision history } \\
\hline Yes & 28 & 10 & $1.584(0.748,3.354)$ & $1.531(0.681,3.443)$ \\
\hline No & 258 & 146 & 1 & 1 \\
\hline
\end{tabular}

${ }^{a}$ statistically significant at $p$-value $<0.001$ 
of Gondar Ethiopia (77.6\%), Mansoura, Egypt (75\%), Pakistan (78\%), Iran (73.2\%), and Saveetha University (70.4\%) [26, 30-35]. This is due to the study setting, age of study participants, and most of the studies did not differentiate whether the dysmenorrhea is primary or secondary.

In this particular study, a positive family history of dysmenorrhea and irregular menstrual cycle are the determinant factors of primary dysmenorrhea. The study revealed that females who had a positive family history of dysmenorrhea were five times more likely to develop primary dysmenorrhea $[\mathrm{AOR}=5.19,95 \% \mathrm{CI}: 3.21,8.37]$ compared to those who had no family history of dysmenorrhea. This is supported by a study in Turkey [31], Iran [30], Eastern, Benin [36], Serbia [37], and Australia [38]. This is related to genetic linkage between the mother and the child that makes to develop menstrual pain. Studies suggest that genetic background influences the severity of dysmenorrhea [39].

Having an irregular monthly menstrual cycle is the determinant factor of primary dysmenorrhea. Female students who had irregular monthly menstrual cycle is nearly two times more likely to develop primary dysmenorrhea compared to those having regular monthly menstrual cycle $[\mathrm{AOR}=1.701,95 \% \mathrm{CI}: 1.02,2.84]$. No studies showed the relationship between the irregular monthly menstrual cycle and menstrual pain but it is associated with prostaglandin secretion. The author only used reports obtained from the respondents, no clinical examination was done. Since most studies conducted dysmenorrhea as a combined manner (primary and secondary dysmenorrhea) the author forced to discuss the current study with those studies. Further research is needed to find out the real cause of primary dysmenorrhea.

\section{Conclusions}

The prevalence of primary dysmenorrhea among female students found to be high. Irregular monthly menstrual cycle and positive family history of dysmenorrhea are determinant factors of primary dysmenorrhea. Absenteeism from school was the main impact of primary dysmenorrhea. Hence, researching primary dysmenorrhea significantly improves its impact by educating females about the management of primary dysmenorrhea.

\section{Abbreviations}

AOR: Adjusted Odds Ratio; Cl: Confidence Interval; COR: Crude Odds Ratio; IUCD: Intrauterine Contraceptive Device; NRS: Numeric Rating Scale

\section{Acknowledgments}

The authors would like to thank the ethical review committee of the school of nursing at the University of Gondar, study participants, and data collectors for their collaboration during the data collection.

\section{Authors' contributions}

AWA conceived the idea and wrote the proposal, participated in the data collection process, analyze data, and draft the paper. DGK and TAW approved the proposal with some revisions, participated in data analysis, and reviewed the manuscript. All the authors approved the final draft of the manuscript.

\section{Funding}

No funding was received for this study.

\section{Availability of data and materials}

The raw data would not be provided for the reason of protecting patients' confidentiality but, the summary data are available in the main document.

\section{Ethics approval and consent to participate}

The study was approved by the school of the nursing ethical review committee of the University of Gondar with reference number S/N/178/2017. Verbal informed consent was obtained from each study participant. No personal identifiers such as name, ID number, and phone number were used. The information obtained from each study participants was kept secured, locked, and stored as an electronic dataset.

\section{Consent for publication}

Not applicable.

\section{Competing interests}

The authors have declared that they have no competing interests.

\section{Author details}

${ }^{1}$ Department of Medical Nursing, School of Nursing, College of Medicine and Health Sciences, University of Gondar, Gondar, Ethiopia. ${ }^{2}$ Department of Pediatrics and Child Health Nursing, School of Nursing, College of Medicine and Health Sciences, University of Gondar, Gondar, Ethiopia. ${ }^{3}$ Department of Surgical Nursing, School of Nursing, College of Medicine and Health Sciences, University of Gondar, Gondar, Ethiopia.

Received: 16 May 2018 Accepted: 24 December 2019

Published online: 06 January 2020

\section{References}

1. Dawood M. Dysmenorrhea. J Reprod Med. 1985;30(3):154-67.

2. Friederich MA. Dysmenorrhea. Women Health. 1983;8(2-3):91-106.

3. Lefebvre G, Pinsonneault O, Antao V, Black A, Burnett M, Feldman K, et al. Primary dysmenorrhea consensus guideline. J Obstet Gynaecol Can. 2005;27(12):1117-46.

4. Ju H, Jones M, Mishra G. The prevalence and risk factors of dysmenorrhea. Epidemiol Rev. 2013;36(1):104-13.

5. Johnston L. Menstrual pain (dysmenorrhoea). Prof Nurs Today. 2014;18(1):13-4.

6. Smith R, Kaunitz A. Primary dysmenorrhea in adult women: clinical features and diagnosis. Alphen aan den Rijn: Wolters Kluwer; 2015.

7. Berkley KJ. Primary dysmenorrhea: an urgent mandate. Pain. 2013;1(1):8.

8. Zahradnik H, Breckwoldt M. Contribution to the pathogenesis of dysmenorrhea. Arch Gynecol. 1984;236(2):99-108.

9. Åkerlund M. Pathophysiology of dysmenorrhea. Acta Obstet Gynecol Scand. 1979;58(sup87):27-32.

10. Abdel-Salam DM, Alnuman RW, Alrwuaili RM, Alrwuaili GA, Alrwuaili EM. Epidemiological aspects of dysmenorrhea among female students at Jouf University, Saudi Arabia. Middle East Fertil Soc J. 2018;23(4):435-9.

11. Gagua T, Tkeshelashvili B, Gagua D. Primary dysmenorrhea: prevalence in adolescent population of Tbilisi, Georgia and risk factors. J Turk Ger Gynecol Assoc. 2012;13(3):162.

12. Minaleshewa Biruk Gebeyehu YGT, Bejiga GS, Mekuria AB, Andarge DA, Debay YB, Gebresillassie BM. Prevalence, impact and Management Practice of Dysmenorrhea among University of Gondar Students, Northwestern Ethiopia: A Cross-Sectional Study. Hindawi Int J Reprod Med. 2017;2017:8. https://doi.org/10.1155/2017/3208276

13. Burnett MA, Antao V, Black A, Feldman K, Grenville A, Lea R, et al. Prevalence of primary dysmenorrhea in Canada. J Obstet Gynaecol Can. 2005;27(8):765-70

14. Akiyama S, Tanaka E, Cristeau O, Onishi Y, Osuga Y. Evaluation of the treatment patterns and economic burden of dysmenorrhea in Japanese women, using a claims database. Clinicoecon Outcomes Res. 2017:9:295.

15. Dawood MY. Primary dysmenorrhea: advances in pathogenesis and management. Obstet Gynecol. 2006;108(2):428-41.

16. De Sanctis V, Soliman A, Bernasconi S, Bianchin L, Bona G, Bozzola M, et al. Primary dysmenorrhea in adolescents: prevalence, impact and recent knowledge. Pediatr Endocrinol Rev. 2015;13(2):512-20. 
17. Nahid K, Fariborz M, Ataolah G, Solokian S. The effect of an Iranian herbal drug on primary dysmenorrhea: a clinical controlled trial. J Midwifery Womens Health. 2009;54(5):401-4.

18. Karampour E, Khoshnam E, Khoshnam MS, Mohammadi HR, Jahromi FZ, Nikseresht AA. The effect of massage training on primary dysmenorrhea. Adv Environ Biol. 2012. p. 3040-3.

19. Durain D. Primary dysmenorrhea: assessment and management update. J Midwifery Womens Health. 2004;49(6):520-8.

20. Hailemeskel S, Demissie A, Assefa N. Primary dysmenorrhea magnitude, associated risk factors, and its effect on academic performance: evidence from female university students in Ethiopia. Int J Women's Health. 2016;8:489.

21. Yamamoto K, Okazaki A, Sakamoto Y, Funatsu M. The relationship between premenstrual symptoms, menstrual pain, irregular menstrual cycles, and psychosocial stress among Japanese college students. J Physiol Anthropol. 2009:28(3):129-36.

22. Breivik $H$, Borchgrevink $P$, Allen $S$, Rosseland L, Romundstad L, Breivik Hals E, et al. Assessment of pain. BJA. 2008;101(1):17-24.

23. Awoke Giletew WB. Prevalence and associated factors of primary dysmenorrhea among Debre Tabor University students, north Central Ethiopia. Int J Biomed Eng Clin Sci. 2019;4(4):70-4.

24. Ahuja A, Sharma MK, Singh A. Impact of dysmenorrhea on quality of life of adolescent girls of Chandigarh. J Child Adolesc Behav. 2016;4(295):2

25. Margaret A, Burnett VA, Black A, Feldman K, Grenville A, Lea R, Lefebvre G, Pinsonneault O, Robert M. Prevalence of Primary Dysmenorrhea in Canada. J Obstet Gynaecol Can. 2005;27(8):765-70.

26. Sayako Akiyama ET, Cristeau O, Onishi Y, Osuga Y. Evaluation of the treatment patterns and economic burden of dysmenorrhea in Japanese women, using a claims database; 2017.

27. Tinatin Gagua BT. David Gagua. Primary dysmenorrhea: prevalence in adolescent population of Tbilisi, Georgia and risk factors. J Turkish-German Gynecol Assoc. 2012;2012(13):162-8.

28. KMaKN MK. Prevalence of Dysmenorrhea and Its Correlating Lifestyle Factors in Japanese Female Junior High School Students. Ohoku J Exp Med. 2015; 2015(236):107-13.

29. Maitri Shah AM, Sangita Patel, Malay Shah, Harsh Bakshi. A study of prevalence of primary dysmenorrhea in young students healthline. 2013;4(2):30-4.

30. Habibi N, Huang MSL, Gan WY, Zulida R, Safavi SM. Prevalence of Primary Dysmenorrhea and Factors Associated with its intensity among undergraduate students. J Pain Manage Nurs. 2015;16(6):855-61.

31. Alaettin Unsal UA. Mustafa Tozun, Gul Arslan \& Elif Calik. Prevalence of dysmenorrhea and its effect on quality of life among a group of female university students. Ups J Med Sci. 2010;2010(115):138-45.

32. Gebeyehu MB, Mekuria AB, Tefera YG, Andarge DA, Debay YB, Bejiga GS, et al. Prevalence, Impact, and Management Practice of Dysmenorrhea among University of Gondar Students, Northwestern Ethiopia: A Cross-Sectional Study. Int J Reprod Med. 2017;2017:8. https://doi.org/10.1155/2017/3208276.

33. El-Gilany AH, Badawi K, El-Fedawy S. Epidemiology of dysmenorrhoea among adolescent students in Mansoura, Egypt. East Mediterr Health J. 2005:11:155-63.

34. Solomon Hailemeskel AD. Nigussie Assefa. Primary dysmenorrhea magnitude, associated risk factors, and its effect on academic performance: evidence from female university students in Ethiopia. Int J Women's Health. 2016;2016(8):489-96.

35. Saleema Gulzar SK, Abbas K, Arif S, Husain SS, Imran HI. Jacoline Sommer Prevalence, Perceptions and Effects of Dysmenorrhea in School Going Female Adolescents of Karachi, Pakistan. Int J Innovative Res Dev. 2015;4(2):236-40.

36. Sidi IHB, Obossou AAA, Salifou K, Vodouhe M, Denakpo J, Perrin R. Primary Dysmenorrhea in the Schools of Parakou: Prevalence, Impact and Therapeutic Approach. Gynecol Obstet. 2016;6(5).

37. Jankovic APiaS. Riskfactorsfordysmenorrheaamongyoungadultfemaleuniversity students. AnnlstSuperSanità 2016:52(1):98-103.

38. Hong Ju MJ. And Gita Mishra. The prevalence and risk factors of dysmenorrhea. Epidemiol Rev. 2016:2014(36):104-13.

39. Jones AV, Hockley JR, Hyde C, Gorman D, Sredic-Rhodes A, Bilsland J, et al. Genome-wide association analysis of pain severity in dysmenorrhea identifies association at chromosome 1p13. 2, near the nerve growth factor locus. Pain. 2016;157(11):2571

\section{Publisher's Note}

Springer Nature remains neutral with regard to jurisdictional claims in published maps and institutional affiliations.

\section{Ready to submit your research? Choose BMC and benefit from:}

- fast, convenient online submission

- thorough peer review by experienced researchers in your field

- rapid publication on acceptance

- support for research data, including large and complex data types

- gold Open Access which fosters wider collaboration and increased citations

- maximum visibility for your research: over $100 \mathrm{M}$ website views per year

At BMC, research is always in progress.

Learn more biomedcentral.com/submissions 